\title{
Solving the problem of energy efficiency of remote agricultural farms
}

\author{
Sergey Sergeev ${ }^{1, *}$, Sergey Barykin ${ }^{1}$, Olga Kalinina $^{1}$, Elena Naumova $^{2}$, Natalia \\ Dedyukhina $^{3}$, and Tatiana Dmitrieva ${ }^{4}$ \\ ${ }^{1}$ Peter the Great St. Petersburg Polytechnic University, Graduate School of Service and Trade, \\ 195251, St. Petersburg, Russia \\ ${ }^{2}$ Saint Petersburg State Maritime Technical University, Engineering and Economics Faculty, 190121, \\ St. Petersburg, Russia \\ ${ }^{3}$ Emperor Alexander I St. Petersburg State Transport University, Department of Accounting and \\ Audit, 190031, St. Petersburg, Russia \\ ${ }^{4}$ Peter the Great St. Petersburg Polytechnic University, Graduate School of Management and \\ Business, 195251, St. Petersburg, Russia
}

\begin{abstract}
The research focuses on the viability of a mathematical model of energy efficiency of agricultural sector for the case of Russia. The article describes the methodology and results of research aimed at improving energy efficiency in the activities of remote farms of the agroindustrial complex. The emphasis is placed on the application of a scientific approach based on mathematical modeling of work on a limited resource. For this purpose, the most common solutions are SAN (Storage Area Network), while the programs that are common for enterprises of the network are located on cloud servers. The results of the research were applied in a joint project with the Catalan Polytechnic University (Polytechnic University of Catalonia).
\end{abstract}

\section{Introduction}

To solve the strategic objectives of the agricultural development program, it is necessary not only to restore the largely lost potential of the agro-industrial complex, but also to carry out serious work on the introduction of modern scientific methods.

Some issues regarding the impacts on reducing waste, pollution and emission of greenhouse gases are studied in [1]. The environmental innovations could be considered as green supply chain management [2]. Vine, E; Nakagami, H; Murakoshi, C study the ways to provide the energy efficiency and energy services to utility customers [3]. Vine, E, in his study wrote that energy service companies (ESCOs) are expected to play an important role in promoting energy efficiency in countries outside the United States [4].

According to Umberto Berardi in his article «Building energy consumption in US, EU, and BRICS countries», such important questions as energy shortage and increase in GHG emissions, have raised many concerns worldwide about current trends in energy

\footnotetext{
*Corresponding author: sergeev2@inbox.ru
} 
consumption [5]. Energy savings opportunities may be explored through the deployment of solar hot water/steam generation systems to reduce carbon emissions from the plant [6].

Tanushree Bhattacharya and Richa Kapoor are discussing energy savings in India showing that the industry that pollutes nature spends the most energy [7]. Energy management is essential in both financial and environmental aspects [8]. The development of assessment standards for green building in China and the development of green building technologies are studied in [9]. China's energy saving in different fields are investigated by [10]. The building energy savings business model needs integration with other housing association services in Finland [11]. Some researchers focuse on the viability of a business model based on energy efficiency contracts [12], energy efficiency services [13], energyefficient system resulting in environmental benefits for the project stakeholders and the entire society [14].

Russia offers an interesting example due to its enormous potential for energy conservation, energy efficiency program in the public sector [15]. This implies close collaboration of specialists of the agro-industrial complex with scientists, and as a result, if an innovative approach [16] is taken, it should lead to the creation of optimized technologies [17], expert systems, and fundamentally new methods focused on the needs of commodity producers.

First of all, the efforts of scientists were focused on the problems associated with import substitution. The well-known plan "road map" of the Government of the Russian Federation is aimed at protecting the domestic producer and increasing the competitiveness of domestic products. Here it is necessary to emphasize that in the process of increasing agricultural production, energy consumption inevitably increases. According to today's data, an increase in production by $1 \%$ leads to an increase in energy consumption by $2-3$ $\%$. Suffice it to say that in our country, per 1 ha of arable land, the cost is $250-280 \mathrm{~kg}$ of conventional fuel. At the same time, in the United States of America, no more than half, about $140 \mathrm{~kg}$. According to this indicator, our agro-industrial complex cannot compete with the countries of Europe, the USA, Canada and Japan. This is due to the fact that these countries have long switched to energy-saving technologies, have implemented for decades a well-established system of measures, both technical and organizational, elaborated in detail and based primarily on economic calculation and scientific methods.

\section{Problem statement}

The use of serious mathematical models [18], the widespread introduction of computerized systems [19], has allowed in Europe to increase the share of energy costs in the cost of products to $7 \%$ and even lower. In Russia, this indicator hovers at levels above $20 \%$. This allows us to conclude that there is a great potential for the development and application of scientifically based modernization of technological processes in the direction of reducing energy costs and resource conservation.

This paper deals with the complex problem of limited resource [20] and the development of computer control algorithms aimed at application in remote agricultural farms. This class of objects includes the vast majority of livestock and crop production enterprises distributed throughout Russia.

When analyzing this problem, it should be taken into account that the main consumer of agricultural products is retail chains [21]. Over the past 15 years, their share has grown to $80 \%$ of the total volume [22] of trade. In addition, the segment of the Privat Label, which accounts for up to a quarter of the turnover of retail chains, has become a fundamentally influencing factor [23]. Based on this, if there are optimization practices for network trading enterprises consisting of retail sites, cross-docking, wholesale warehouses and a consolidated transport pool, then their use is most appropriate in large cities. 
To maintain effective interaction with rural agribusiness entities, it is necessary to adapt their algorithms [24] and software [25] to the specific conditions of such business. When setting the task, it is necessary to take into account the statistics that show that in the Russian Federation, the area of crops and livestock are constantly decreasing.

Attempts to compensate for this circumstance by increasing productivity and productivity do not lead to the desired result. The decrease in the removal of mineral and organic fertilizers led to a drop in soil fertility. To determine the optimal mode of energy consumption [26], it was necessary to solve the problem of using a limited natural resource for the needs of the agro-industrial complex.

\section{Mathematical model}

Thus, in principle, it is possible to formalize [27] the problem of using existing natural and production capacities. Based on this, in the problem under consideration [28], it is necessary to take into account multidirectional processes on the selected planning horizon. This is an increase in the load on the available resource and the resulting decrease in the quality of this type of shared resource, with a simultaneous assessment of the negative component of the impact of ongoing processes.

Formalized [29] we present a given number of commercial entities - users of the resource. Their number is denoted by $n$. Denote the intensity [30] of consumption $R_{\Sigma}$ (rich) of each of them as $r_{i}$, where $i=1 \ldots n$, then we write the situation in vector form:

$$
\bar{R}=\left(r_{1}, r_{2}, \ldots, r_{n}\right)
$$

at the same time, the total load on $R_{\Sigma}$ the resource is equal to:

$$
R_{\Sigma}=\sum_{i=1}^{n} r_{i}
$$

Next, we set the value of the weighted average variable costs $V$ and the function $\gamma(r)$ that reflects the value of the economic benefit [31] from the unit of load of each user.

It is natural to assume that with the total load, starting from a certain number $R_{\Sigma}>R_{\Sigma 0}$, the performance decreases both due to the presence of other competing users, and due to the saturation of the resource. This can be expressed by the relation:

$$
\gamma^{\prime}(r)<0 \text {. }
$$

Accordingly, guided by the influence of the same reasons, we will add factors related to the negative component [32] of the impact of the activities of these users on the resource and its natural limitations. Then the second derivative also satisfies the inequality:

$$
\gamma^{\prime \prime}(r)<0 \text {. }
$$

Let's write down the ratio for calculating the commercial profit of $i-$ the th user as

$$
Q_{i}=r_{i} \gamma\left(r_{1}+r_{2}+\ldots+r_{n}\right)-V r=r_{i} \gamma(\Omega)-V r_{i}
$$

Then, assuming the existence of a Nash equilibrium [33], there must be a value of $i-$ the user $r_{i}^{*}$ load at which the value of expression (4) reaches the maximum for the remaining components [34] of the vector (1):

$\bar{R}_{i}^{*}\left(r_{1}^{*}, r_{2}^{*}, \ldots, r_{i-1}^{*}, r_{i+1}^{*}, \ldots, r_{n}^{*}\right)$ 
To do this, taking the partial derivatives $\frac{\partial Q_{i}}{\partial r_{i}}$, from the condition $\frac{\partial Q_{i}}{\partial r_{i}}=0$, by $i=1 \ldots n$ and denoting: $r_{-i}^{*}=\sum_{k \neq i} r_{k}^{*}$,

we get: $\gamma\left(r_{i}+r_{-i}^{*}\right)+r_{i} \gamma^{\prime}\left(r_{i}+r_{-i}^{*}\right)-V=0$, for $i=1 \ldots n$.

Summing up at the desired equilibrium point $R_{\Sigma}{ }^{*}$, we get the equation:

$$
R_{\Sigma}{ }^{*}=n \frac{V-\gamma\left(R_{\Sigma}{ }^{*}\right)}{\gamma^{\prime}\left(R_{\Sigma}{ }^{*}\right)} .
$$

If we compare this expression with the search for the maximum in terms of the leveloptimal resource use [35] by a pool of consumers, then the extremum of the equation will be reached when performing:

$$
R_{\Sigma}{ }^{*}=\frac{V-\gamma\left(R_{\Sigma 0}\right)}{\gamma^{\prime}\left(R_{\Sigma 0}\right)},
$$

and given (3) and the fact that $n>1$, it is clear from (5) that $R_{\Sigma}{ }^{*}>R_{\Sigma 0}$.

A practical interpretation of this can be the following example: a remote livestock farm that exploits pastures, sown areas for growing forage crops. As a result of the calculation, we get an optimized load and the corresponding values of the required energy resources, such as electricity, heat, fuel, and fuel.

In addition, such an optimization calculation will make it possible to use the potential of natural resources more evenly, improve the environment, and avoid irreversible depletion of soils and pollution of water bodies. Further, it should be noted that there is a huge potential for introducing modern business applications based on the latest achievements of IT technologies into the management practice of agro-industrial enterprises. This is primarily due to the fact that Russia continues to consolidate agricultural production under single network brands. This approach, of course, allows for a unified marketing and distribution policy. This should also include the Privat Label segment, which serves as the main link in the chain of the agro-industrial complex network-retail chains. The importance of a science-based solution at the heart of the entire structure of their relationship cannot be overemphasized. This includes the reduction of fuel and lubricants consumption due to verified logistics, the full use of the consolidated transport pool, energy costs associated with the storage of agricultural products in refrigerated intermediate warehouses using cross-docking technology, etc. The key point in the formation of algorithms, for software developers [36], will be a significant geographical dispersion of enterprises involved in the activities of the agro-industrial complex. This requires the use of modern approaches both in the methodological aspect and in the field of practical implementation. In particular, from a technical point of view, today for IT specialists it is not a big problem to place a clustered application if the nodes are located in different geographical locations. For this purpose, the most common solutions are SAN (Storage Area Network), while the programs that are common for enterprises of the network are located on cloud servers. Such solutions were not possible a few years ago due to the lack of stable high-speed access to the global Internet. Another positive factor is the availability of alternative connection methods, such as $3 \mathrm{G}$, LTE. In turn, for the management of enterprises, these resources are recognized as local, which allows in real time not only to conduct operational management, but also to use the full potential of business analytics in order to reach leading indicators. From the user's side, such an organization of the IT structure of common applications is presented as 
a single transparent system. The availability of ready-made packages as part of Windows Server or HA (High Availability) services of IBM Lotus Notes makes it possible to create and develop such systems. Thus, the above features are not restrictions in the process of applying the mathematical modeling apparatus.

\section{Results}

The results of these studies were applied in a joint project with the Catalan Polytechnic University (Polytechnic University of Catalonia). This choice was dictated by a number of considerations, the main of which - significant achievements in the development of modern methods of energy-saving methods of agriculture in Spain, as one of the largest producers in Europe, with a cultivated area of 24.8 million hectares. At the same time, crop production is the leading industry in this country. The results of the calculations. performed on the selected experimental farm, are summarized in Table 1.

Table 1. The set of indicators of energy resources consumed.

\begin{tabular}{|c|c|c|c|c|c|c|c|c|}
\hline \multirow[b]{2}{*}{$\begin{array}{l}\text { Type of } \\
\text { calculation }\end{array}$} & \multicolumn{6}{|c|}{ Energy resources consumed } & \multicolumn{2}{|c|}{ Indicators } \\
\hline & 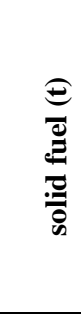 & 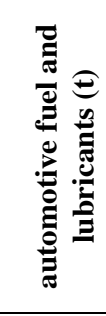 & & 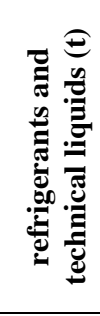 & 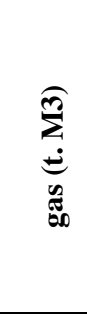 & 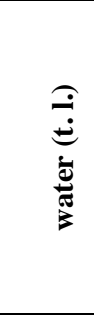 & 흘 & 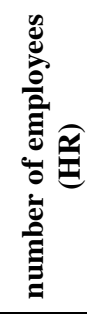 \\
\hline previous value & 204 & 1060 & 170 & 21 & 14 & 7290 & 1340 & 880 \\
\hline $\begin{array}{l}\text { after applying the } \\
\text { technique }\end{array}$ & 198 & 980 & 155 & 20.5 & 13.6 & 7400 & 1390 & 855 \\
\hline \% savings & $2.9 \%$ & $7.55 \%$ & $8.8 \%$ & $2.4 \%$ & $2.8 \%$ & $-1.5 \%$ & $-3.7 \%$ & $2.8 \%$ \\
\hline
\end{tabular}

Important notes need to be made here:

1. The analysis takes into account the EU subsidies paid to farmers depending on the size of their existing olive groves - at the rate of 300-400 euros per hectare per year.

2. The peculiarity of the Extremadura region, on the data of which the calculations were carried out, is the high degree of use of primary renewable energy sources (solar panels, collectors, wind generators), which makes an element of difference from the Russian experience, since today the segment of alternative sources is quite small.

\section{Conclusions}

For Russia, a set of indicators similar to those shown in Table 1 above should look significantly better, and the economic effect is much higher, due to the fact that the processes of innovation implementation in the domestic agro-industrial complex are just beginning and the potential for energy saving is several times higher. During 2018-2020 In the framework of joint activities with the St. Petersburg Polytechnic University and the Basic Department of the St. Petersburg Agrarian University, the use of technical and technological types of modernization aimed at introducing innovative methods of energy saving in the agro-industrial complex will be tested in the farms of the Leningrad Region.

The algorithms obtained in the presented work serve primarily to solve such fundamental issues for agriculture as improving the competitiveness of products, radical modernization, which is based on the energy saving paradigm. The key in this case is a 
verified scientific calculation and mathematical models implemented in expert systems of managers of the agro-industrial complex.

\section{References}

1. Y. Kayikci, Procedia Manufacturing 21, 782 (2018)

2. J. Sarkis, Journal of Cleaner Production 11, 397 (2003)

3. E. Vine, H. Nakagami, and C. Murakoshi, 24, 479 (2000)

4. E. Vine, Energy Policy 33, 691 (2005)

5. U. Berardi, Procedia Engineering 118, 128 (2015)

6. A. K. K. Pandey and R. Prakash, Open Journal of Energy Efficiency 07, 89 (2018)

7. T. Bhattacharya and R. Kapoor, Renewable and Sustainable Energy Reviews 16, 1311 (2012)

8. A. Mokhtar and M. Nasooti, Energy Strategy Reviews 28, 100458 (2020)

9. Y. Zhang, J. Kang, and H. Jin, Energies 11 (2018)

10. Y. F. Wang, K. P. Li, X. M. Xu, and Y. R. Zhang, Renewable and Sustainable Energy Reviews 29, 641 (2014)

11. N. Suhonen and L. Okkonen, Energy Policy 61, 783 (2013)

12. S. Pätäri and K. Sinkkonen, Journal of Cleaner Production 66, 264 (2014)

13. B. Duplessis, J. Ô. Adnot, M. Dupont, and F. Racapé, Energy Policy 45, 268 (2012)

14. X. Zhang, Z. Wu, Y. Feng, and P. Xu, Journal of Cleaner Production 109, 166 (2015)

15. V. Roshchanka and M. Evans, Journal of Cleaner Production 112, 3905 (2016)

16. S. Barykin and A. Kobicheva, in MATEC Web of Conferences (2018)

17. O. Kalinina, S. Firova, S. Barykin, and I. Kapustina, Development of the Logistical Model for Energy Projects' Investment Sources in the Transport Sector (Springer Verlag, 2020)

18. A. S. Volkova and V. V Provotorov, Russian Mathematics 58, 1 (2014)

19. V. V. Provotorov, V. I. Ryazhskikh, and Y. A. Gnilitskaya, Vestnik SanktPeterburgskogo Universiteta, Prikladnaya Matematika, Informatika, Protsessy Upravleniya 13, 264 (2017)

20. V. V. Provotorov and E. N. Provotorova, Vestnik Sankt-Peterburgskogo Universiteta, Prikladnaya Matematika, Informatika, Protsessy Upravleniya 13, 209 (2017)

21. S. Sergeev and T. Kirillova, IOP Conference Series: Materials Science and Engineering 666 (2019)

22. S. M. Sergeev, A. A. Kurochkina, O. V. Lukina, and V. E. Zasenko, IOP Conference Series: Materials Science and Engineering 918 (2020)

23. A.S. Golosnoy, V.V. Provotorov, S.M. Sergeev, L.B. Raikhelgauz, and O.J. Kravets, Journal of Physics: Conference Series 1399 (2019)

24. L.N. Borisoglebskaya, E. N. Provotorova, and S. M. Sergeev, Journal of Physics: Conference Series 1399 (2019)

25. V.V. Provotorov, D.V. Danilevich, A.A. Fedotov, S.M. Sergeev, and O.J. Kravets, IOP Conference Series: Materials Science and Engineering 862 (2020)

26. A.A. Fedotov, S.M. Sergeev, E.N. Provotorova, T.V. Prozhogina, and O.Y. Zaslavskaya, IOP Conference Series: Materials Science and Engineering 862 (2020) 
27. O.V. Pilipenko, E.N. Provotorova, S.M. Sergeev, and O.V. Rodionov, Journal of Physics: Conference Series 1399 (2019)

28. L.N. Borisoglebskaya, S.M. Sergeev, E.N. Provotorova, and A.A. Zaslavskiy, IOP Conference Series: Materials Science and Engineering 862 (2020)

29. V.V. Provotorov, S.M. Sergeev, and A.A. Part, Vestnik Sankt-Peterburgskogo Universiteta, Prikladnaya Matematika, Informatika, Protsessy Upravleniya 15, 107 (2019)

30. S. Krasnov, E. Zotova, S. Sergeev, A. Krasnov, and M. Draganov, IOP Conference Series: Materials Science and Engineering 618 (2019)

31. S. Krasnov, S. Sergeev, E. Zotova, and N. Grashchenko, E3S Web of Conferences 110 (2019)

32. S. Krasnov, S. Sergeev, A. Titov, and Y. Zotova, IOP Conference Series: Materials Science and Engineering 497 (2019)

33. L. N. Borisoglebskaya, E. N. Provotorova, and S. M. Sergeev, IOP Conference Series: Materials Science and Engineering 537 (2019)

34. L. N. Borisoglebskaya, E. N. Provotorova, S. M. Sergeev, and A. P. Khudyakov, IOP Conference Series: Materials Science and Engineering 537 (2019)

35. L. N. Borisoglebskaya, V. V. Provotorov, S. M. Sergeev, and E. S. Kosinov, IOP Conference Series: Materials Science and Engineering 537 (2019)

36. S. Y. Barykin, I. V. Kapustina, S. M. Sergeev, and V. K. Yadykin, Journal of Open Innovation: Technology, Market, and Complexity 6, 1 (2020) 